\title{
Martensitic transformation in Ti-Ni-Cu shape memory wires broken by thermal cycling under constant load
}

\author{
C.J. de Araújo, M. Morin ${ }^{1}$ and G. Guénin ${ }^{1}$
}

Departamento de Engenharia Mecânica, Universidade Federal da Paraíba, Caixa Postal 10069, Cep. 58109-970, Campina Grande - PB, Brazil

${ }^{1}$ GEMPPM, UMR 5510 du CNRS, INSA de Lyon, 20 avenue Albert Einstein, 69621 Villeurbanne, France

\begin{abstract}
:
In this paper, the physical properties of a $\mathrm{Ti}-45.0 \mathrm{Ni}-5.0 \mathrm{Cu}(\% \mathrm{at})$ alloy are studied after failure (rupture) by thermal cycling under constant load between $75 \mathrm{MPa}$ and $350 \mathrm{MPa}$. Transformation temperatures measured by electrical resistance (ER) change and DSC techniques show a good agreement in the virgin specimens, however this is not the case for the failed material. In addition, for wires broken under stresses until $125 \mathrm{MPa}$, the DSC peaks becomes sharper than the ones measured with the virgin wires. In all cases, the relative change of ER associated to the martensitic transformation in the failed wires was higher than the value measured in the virgin material. These results are discussed essentially considering the role of the oriented defects and internal stresses created in the wires during thermal cycling under constant load.
\end{abstract}

\section{INTRODUCTION}

It is well established that the thermoelastic martensitic transformation is at the origin of the shape memory phenomena in many alloys $[1,2]$. Among these systems, Ti-Ni based alloys are considered the best because of their excellent shape memory characteristics and biocompatibility which are favorable for many potential applications [2]. In general, the martensitic transformation of $\mathrm{Ti}-\mathrm{Ni}$ based alloys were well studied as a function of some typical thermomechanical treatments including solution treatment, annealing after cold working and aging after solution treatment [3-6]. In some cases, the fabrication of shape memory elements is carried out by cold working in martensitic state. After this procedure, the plastically deformed martensite shows a complex structure including dislocations, vacancies and stabilized martensite variants [5-7]. These non-oriented defects are responsible for a total or partial stabilization of martensite variants causing a reduction of the transformed fraction during heating of the material. As a consequence a decrease of the heat of transformation is observed as well as a decrease of the transformation temperatures (in relation to recrystallized state) after the first heating corresponding to the reverse transformation [8,9]. Additionally, it has been confirmed that recrystallized Ti-Ni specimens submitted to thermal cycling without applied stress exhibit a decrease in heat of transformation [4, 10] accompanied with a decrease of the martensitic transformation start temperature $\left(\mathrm{M}_{\mathrm{S}}\right)[3,4]$ as a result of the introduction of dislocations. However, it is still lacking in literature some experimental results concerning the transformation of $\mathrm{Ti}-\mathrm{Ni}$ based alloys plastically deformed by a particular thermomechanical treatment as, for example, thermal cycling under mechanical load. Thus, the major aim of this work is to clarify the transformation behavior of Ti-45.0Ni-5.0 Cu (at $\%$ ) specimen wires failed after a large number of thermal cycles under constant load.

\section{EXPERIMENTAL PROCEDURE}

The material used in this study were commercial Ti-45.0Ni-5.0Cu (at $\%)$ wires with $0.55 \mathrm{~mm}$ diameter after cold drawing of about $40 \%$. As received materials were heat treated at $425^{\circ} \mathrm{C}$ for $1 \mathrm{~h}$ followed by cooling at room temperature. Table 1 shows the transformation temperatures and thermal hysteresis $\left(\mathrm{H}_{\mathrm{t}}\right)$ related to the martensitic transformation under stress free conditions obtained by Electrical Resistance (ER) change and DSC (Mettler TA3000) measurements. The stability of these thermal properties as a 
function of the number of thermal cycles was also verified and the superposition of 20 cycles between 0 and $110^{\circ} \mathrm{C}$ has confirmed an excellent thermal stability of the transformation characteristics in absence of external stresses. In addition, a very weak increase of electric resistance in martensitic (measured at $10^{\circ} \mathrm{C}$ ) and austenitic states (measured at $150^{\circ} \mathrm{C}$ ) indicates that probably there is no introduction of defects into the material [11].

Table $\mathrm{l}$ - Thermal properties of the heat treated $\mathrm{Ti}-\mathrm{Ni}-\mathrm{Cu}$ wires (here called virgin material).

\begin{tabular}{|c|c|c|c|c|c|}
\hline Technique & $\mathrm{M}_{\mathrm{f}}\left({ }^{\circ} \mathrm{C}\right)$ & $\mathrm{M}_{\mathrm{S}}\left({ }^{\circ} \mathrm{C}\right)$ & $\mathrm{A}_{\mathrm{S}}\left({ }^{\circ} \mathrm{C}\right)$ & $\mathrm{A}_{\mathrm{f}}\left({ }^{\circ} \mathrm{C}\right)$ & $\mathrm{H}_{\mathrm{t}}\left({ }^{\circ} \mathrm{C}\right)$ \\
\hline DSC & 31.5 & 39.0 & 47.5 & 57.5 & 17.5 \\
\hline ER change & 30.0 & 39.0 & 46.0 & 58.5 & 18.0 \\
\hline
\end{tabular}

The Ti-Ni-Cu wires were tested during the thermal cycling under constant load (uniaxial tensile) mode with an apparatus presented in a previous paper [12] and originally designed for fatigue tests. Specimens having a gauge length between 25 and $30 \mathrm{~mm}$ were loaded by weights in martensitic phase, then heated above $A_{f}$ and the temperature cycling was started. Constant applied stresses were set between 75 and $350 \mathrm{MPa}$. For all stress levels, temperature cycles were carried out between $10^{\circ} \mathrm{C}$ and $154^{\circ} \mathrm{C}$ measuring at the same time the deformation and ER change of the wire as function of the temperature. The wire specimens were first pre-cycled during 20 cycles and afterwards tested until failure by a special logharitimic law of cycling involving classical thermal cycles by forced convection in a silicone oil medium and electrical cycles by Joule effect in the same environment maintained at low temperature $\left(\sim 10^{\circ} \mathrm{C}\right)[12]$.

\section{RESULTS}

The specimens wires were thermally cycled under load (75-350MPa) until fracture. The evolution of

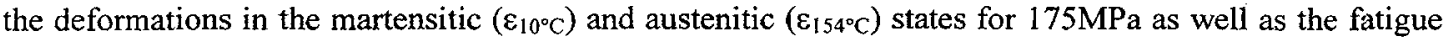
life of the wires are shown in figure $1(\mathrm{a})$ and $1(\mathrm{~b})$, respectively. The stress assisted two-way memory effect (SATWME) is calculated in figure 1 (a) as the difference between $\varepsilon_{10^{\circ} \mathrm{C}}$ and $\varepsilon_{154^{\circ}} \mathrm{C}$. The progressive accumulation of these deformations with cycling is proportional to the applied stress and characterize a creep deformation of the wire. It is observed in figure 1(a) that failure occurs suddenly without degradation of the SATWME immediately before fracture. The Wohler curve of the wires is pointed out in figure $1(\mathrm{~b})$.
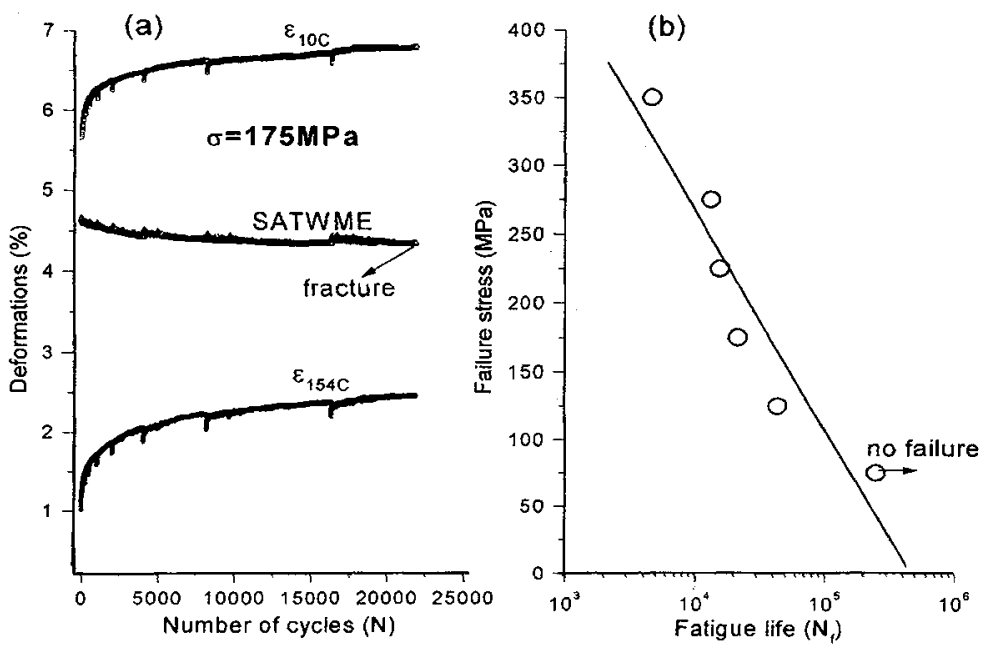

Figure 1 - Some thermomechanical properties of the Ti-Ni-Cu wires during cycling. (a) deformations as a function of the number of cycles for applied stress of $175 \mathrm{MPa}$. (b) fatigue life as function of the applied stresses. 
Specimens broken under various stress levels were analyzed by DSC and ER change measurements. Figure 2 shows the shape of the DSC peaks during cooling (fig.2a) and heating (fig.2b) between 0 and $120^{\circ} \mathrm{C}$ as a function of the applied stress. It is clear that there is a displacement of the peaks towards the higher temperatures when broken specimens are compared to the virgin material (0MPa). This effect exists for all applied stress levels, but this is more important for lower stresses like $125 \mathrm{MPa}$. In addition, the peaks measured during cooling and heating for these lower stresses have intensities higher or close to the ones of the virgin material. Broadening of the peaks is observed for stresses higher than $125 \mathrm{MPa}$.

(a)

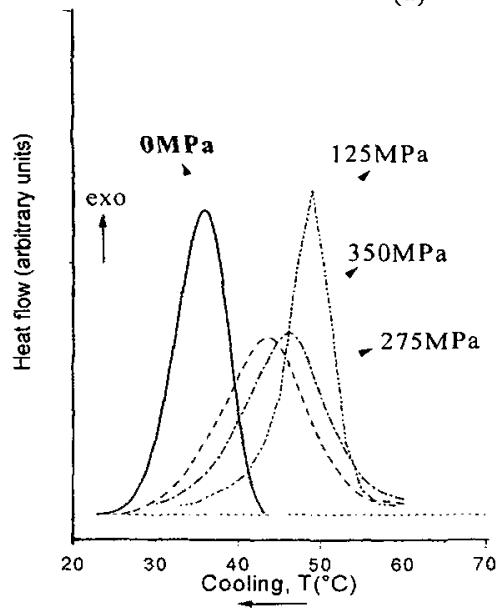

(b)

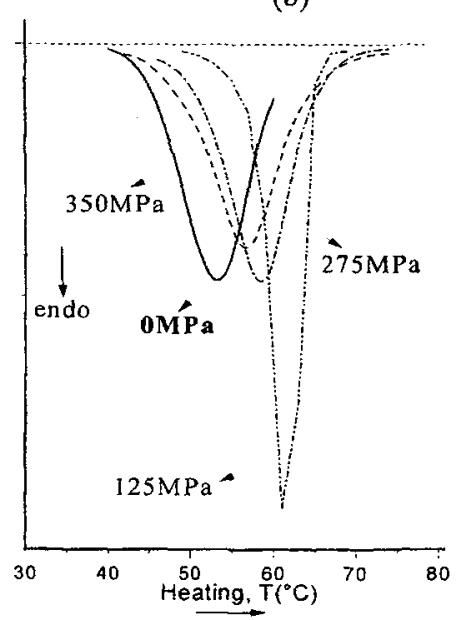

Figure 2-DSC peaks of the specimens failed under different stresses. (a) forward transformation during cooling. (b) reverse transformation during heating.

Figure 3 shows the ER loops for two different failure stresses in comparison with the behavior measured with the virgin wire in absence of external stress. From this figure, the ER change $(\Delta R / R)$ associated to the martensitic transformation is larger in the failed wires in relation to the unloaded virgin material. This phenomenon is followed by a displacement of the ER loops towards the higher temperatures similarly to the results obtained by DSC (figure 2). Additionally, a reduction of thermal hysteresis is also observed. During cycling (N 50) of the failed wires in absence of external stress it has been observed a downwards displacement of the ER loops shown in figure 3 [11]. This behavior characterize a progressive decreasing of the electrical resistivity of the two phases (martensite and austenite) during cycling. However, it was confirmed that thermal properties, like $M_{S}$ and thermal hysteresis, are almost unaffected by cycling.

A comparison between the $\mathrm{M}_{\mathrm{S}}$ temperature measured by DSC and ER change is realized in figure 4(a), while figure 4 (b) shows the heats of transformation measured by DSC during the forward $\left(\Delta \mathrm{H}_{\mathrm{A}-\mathrm{M})}\right.$ and reverse $\left(\Delta \mathrm{H}_{\mathrm{M}-\mathrm{A}}\right)$ transformation. These figures confirm an increase of the $\mathrm{M}_{S}$ temperature and a gradual reduction of the heat flow for failure stresses higher than $125 \mathrm{MPa}$.

\section{DISCUSSION}

According to figure 1(a), there is a progressive accumulation of plastic deformation under load during fatigue cycling. A fraction of this deformation remains after failure and therefore the wires are workhardened during the repeated transformation cycles under load. The defects associated to this work-harde 

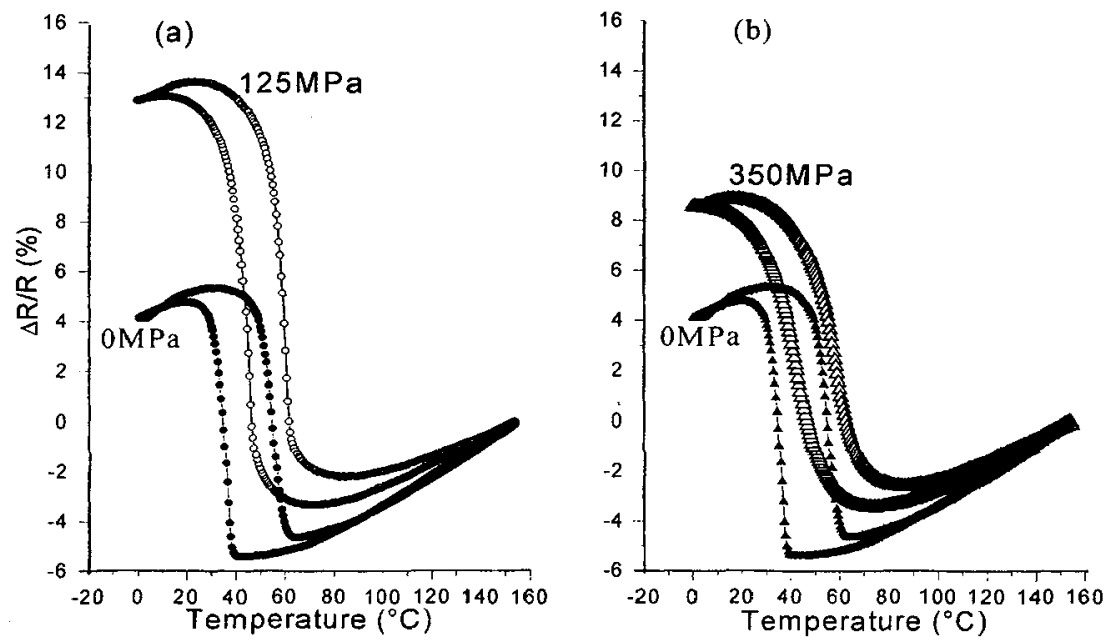

Figure 3 - ER loops after rupture for some applied stress levels. (a) $125 \mathrm{MPa}$. (b) $350 \mathrm{MPa}$.
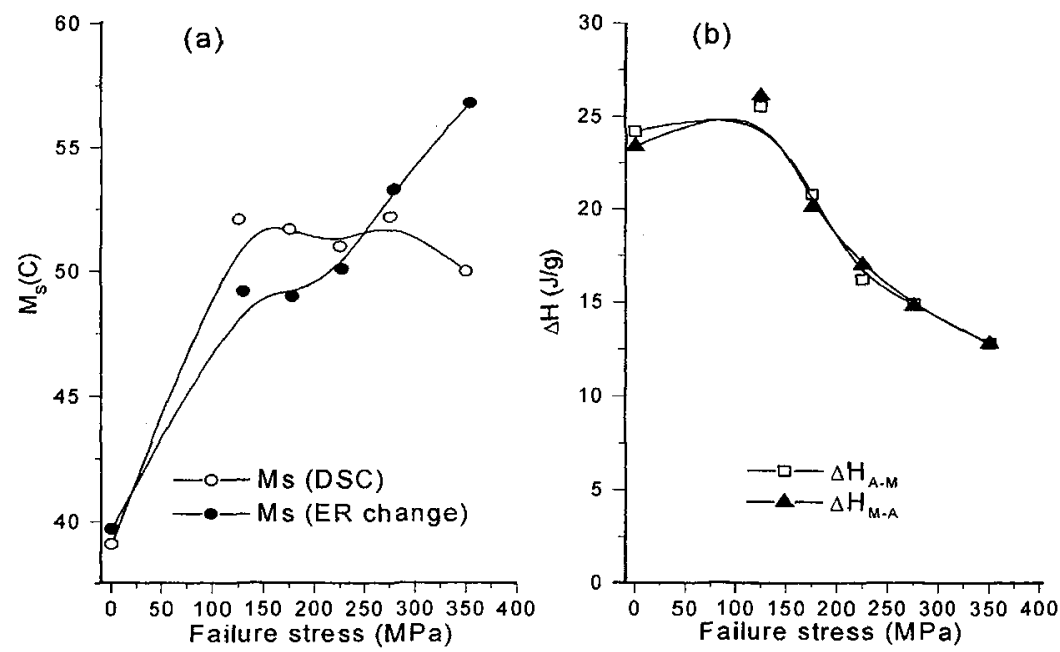

Figure 4 - Thermal properties of broken wires as a function of the applied stress. (a) $M_{S}$ temperature measured by DSC and ER change. (b) enthalpies associated to the forward and reverse transformation.

ning process should be well oriented by the uniaxial tensile stress applied upon the wire. This phenomenon is responsible by the creation of an internal stress field into the material [13].

The broadening of DSC peaks (fig. 2) cause a decrease of the transformation enthalpies in failed wires (fig.4b). This behavior is similar to the one observed in Ti-Ni based alloys plastically deformed (until $40 \%$ ) in martensitic state $[6,8,9]$ and also in recrystallized Ti-Ni alloys submitted to thermal cycling in absence of applied stress [10]. On the other hand, figure 4(a) confirms that there is always an increase of $M_{S}$ after rupture of the wires by thermal cycling under constant load. This augmentation of $M_{S}$ indicates that the internal stress field created by the oriented defects assist the transformation during cooling. This is not the case when defects are introduced by plastic deformation of the martensitic and/or austenitic phase where a decrease of $M_{S}$ is verified $[8,9]$. However, the production of defects by the martensitic 
transformation is not the more important phenomenon. Apparently, the presence of the mechanical load during thermal cycling plays a major role because the $M_{S}$ temperature of the virgin wires are unaffected by thermal cycles under stress free conditions [11]. In addition, it is important to notice that the $M_{S}$ temperature of recrystallized $\mathrm{Ti}-\mathrm{Ni}$ based alloys decreases during thermal cycling without applied stress $[3,4]$. Miyazaki et al. [4] has demonstrated that this diminution of $\mathrm{M}_{\mathrm{S}}$ in recrystallized specimens is due to the introduction of a complex arrangement of dislocations created by the transformation cycles. It is clear that these non-oriented dislocations creates internal stresses that can suppress the martensitic transformation similarly to the effect of the plastic deformation of the stable phases during cold-work $[6,8,9]$.

In addition to the observations above delineated, it is necessary to remark the transformation behavior obtained by ER measurements (fig.3). As pointed out in figure 3, broken wires show a variation of ER during transformation higher than the one verified in virgin wires (0MPa). Recently, De Araújo [11] has realized coupled measurements between SATWME and ER change. These measurements have demonstrated that the variation of electrical resistivity (after elimination of the strain contribution) associated to the transformation under load has been always higher than the one of the unloaded material. This is in agreement with others authors $[14,15]$. Consequently, electrical resistivity change due to formation of martensite variants oriented by the stress is larger than the one associated to the formation of self-accommodated variants. Thus, figure 3 seems to indicate that, in broken wires, there is formation and growth of martensite variants preferentially oriented by the internal stress field created during the fatigue process, contrary to the formation of self-accommodated variants in the virgin specimens. Figure 4(a) reveals a significant difference between $\mathrm{M}_{\mathrm{S}}$ temperatures after rupture as measured by DSC and ER change. It must be precised that the length of the specimens used in ER measurements are about 5 times larger than the ones used in DSC, this behavior seems to indicate that there is a non-uniform distribution of defects along of the ER specimens, contrary to the fracture region used in DSC which given a $\mathrm{M}_{S}$ practically independent of the failure stress.

\section{CONCLUSIONS}

After fracture, the failed wires are trained by the thermal cycling under constant load process. Contratily to the results found in classical processes of plastic deformation of SMA's, it was here confirmed that the reduction of the heat of transformation associated to the introduction of defects into the material is always accompanied by an increase of the $\mathrm{M}_{\mathrm{S}}$ temperature. In addition, these defects being oriented by the applied stress, seem to assist the formation and growth of preferentially oriented martensite variants which are responsible for a higher variation of ER in comparison with the one due to the formation of self-accommodated variants in virgin wires. These highest values of $M_{S}$ and variation of ER in failed material seem to confirm the existence of an internal stress field that assist the forward martensitic transformation.

\section{REFERENCES}

[1] H. Funakubo, in Shape Memory Alloys, 1rd edn. (Gordon and Breach Science Publishers, London, 1987).

[2] K. Otsuka, C.M. Wayman, in Shape Memory Materials, edited by K. Otsuka and C. M. Wayman, 1rd edn. (Cambridge University Press, Cambridge, 1998).

[3] R-D Jean, J-B Duh, Scripta Metallurgica et Materialia, 32, n.6, 885 (1995).

[4] S. Miyazaki, Y. Igo, K. Otsuka, Acta Metall., 34, n.10, 2045 (1995).

[5] H. C. Lin, S. K. Wu, T. S. Chou, H. P. Kao, Acta Metall. Mater., 39, n.9, 2069 (1991).

[6] E. Hornbogen, E. Kobus, Z. Metallkd., 87, n.6, 442 (1996).

[7] E. Hornbogen, Z. Metallkd., 86, n.10, 656 (1995).

[8] H. C. Lin, S. K. Wu, Metallurgical Transactions A, 24A, 293 (1993).

[9] H. C. Lin, S. K. Wu, Acta Metall. Mater., 42, n.5, 1623 (1994).

[10] Y. Liu, in Shape Memory Behaviour, Ph.D. Thesis: University of Western Australia (1990). 
[11] C. J. De Araújo, in Comportement Cyclique de Fils en Alliage à Mémoire de Forme Ti-Ni-Cu: Analyse Electro-Thermomécanique, Dégradation et Fatigue par Cyclage Thermique Sous Contrainte, Doctoral Thesis: INSA de Lyon, France (1999).

[12] C. J. De Araújo, M. Morin, G. Guénin, Journal de Physique IV, 7, n.11, C5-501 (1997).

[13] J. Perkins, Scripta Metall., 8, 1469 (1974).

[14] S. Miyazaki, Y. Liu, K. Otsuka, P. McCormick, in Proceedings of the International Conference on the Martensitic Transformation (ICOMAT), Monterey, CA, USA, 1992, p.929.

[15] G. Airoldi, T. Ranucci, G. Riva, A. Sciacca, J. Phys.: Condens. Matter., 7, 3709 (1995). 